\title{
Near-infrared molecular imaging of tumors via chemokine receptors CXCR4 and CXCR7
}

\author{
Manuela Meincke $\cdot$ Sanjay Tiwari $\cdot$ \\ Kirsten Hattermann · Holger Kalthoff • \\ Rolf Mentlein
}

Received: 11 January 2011/ Accepted: 21 June 2011/Published online: 7 July 2011

(C) The Author(s) 2011. This article is published with open access at Springerlink.com

\begin{abstract}
The chemokine CXCL12/SDF-1 and its receptors CXCR4 and CXCR7 play a major role in tumor invasion, proliferation and metastasis. Since both receptors are overexpressed on distinct tumor cells and on the tumor vasculature, we evaluated their potential as targets for detection of cancers by molecular imaging. We synthesized conjugates of CXCL12 and the near-infrared (NIR) fluorescent dye IRDye ${ }^{\circledR} 800 \mathrm{CW}$, tested their selectivity, sensitivity and biological activity in vitro and their feasibility to visualize tumors in vivo. Purified CXCL12-conjugates detected in vitro as low as 500 A764 human glioma cells or MCF-7 breast cancer cells that express CXCR7 alone or together with CXCR4. Binding was time- and concentration-dependent, and the label could be competitively displaced by the native peptide. Control conjugates with bovine serum albumin or lactalbumin failed to label the cells. In mice, the conjugate distributed rapidly. After 1-92 h, subcutaneous tumors of human MCF-7 and A764 cells in immunodeficient mice were detected with high sensitivity. Background was observed in particular in liver within the first $24 \mathrm{~h}$, but also skull and hind limbs yielded some background. Overall, fluorescent CXCL12-conjugates are sensitive and selective probes to detect solid and
\end{abstract}

Electronic supplementary material The online version of this article (doi:10.1007/s10585-011-9403-y) contains supplementary material, which is available to authorized users.

M. Meincke $\cdot$ K. Hattermann $\cdot$ R. Mentlein $(\bowtie)$

Department of Anatomy, University of Kiel, Olshausenstraße 40, 24098 Kiel, Germany

e-mail: rment@anat.uni-kiel.de

S. Tiwari $\cdot$ H. Kalthoff

Division of Molecular Oncology, Institute for Experimental Cancer Research, Comprehensive Cancer Center North, UK S-H, Campus Kiel, 24105 Kiel, Germany metastatic tumors by targeting tumor cells and tumor vasculature.

Keywords Astrocytoma - Breast cancer - Chemokines · Near infrared $\cdot$ Optical imaging $\cdot$ Receptors $\cdot$ Tumor vasculature
Abbreviations
CXCL11 or I-TAC Interferon-inducible T cell $\alpha$ chemoattractant
CXCL12 or SDF-1 Stromal cell-derived factor-1
EGF
RT-PCR Epidermal growth factor Reverse transcription polymerase chain reaction

\section{Introduction}

Diagnosis of cancer, cancer metastasis, precision of surgical resection, monitoring of therapy in preclinical models or in the clinical situation could be greatly improved by effective and simple imaging methods. Optical imaging methods with tumor-targeting molecular probes fluorescent in the near-infrared (NIR) range (emission/excitation 650-900 nm) have the advantage that they allow not only surface, but deeper imaging up to few $\mathrm{cm}$ into the tissue [1], show a high sensitivity and require comparably simple instrumentation. Tumor-selective or -elevated cell surface molecules such as receptors or adhesion proteins are the predominant targets for NIR-conjugates with antibodies [2] or ligands [3, 4]. As a novel approach, we developed and evaluated bioconjugates of chemokines with NIR fluorescent dyes to enable sensitive detection of tumor cells/tumor endothelial cells. 
Chemokines, small (8-15 kDa) chemotactic cytokines, and their receptors play a critical role in tumor initiation, promotion, progression and metastasis [5]. The chemokine SDF-1 (stromal cell-derived factor-1, CXCL12) appears to be of particular importance in tumor biology, especially in tumor metastasis, invasion and angiogenesis. Interaction of SDF-1 with its receptor CXCR4 (also called fusin) that is expressed on some tumor cells directs them to peripheral tissues like lung, liver, lymph nodes or bone marrow where the ligand is constitutively expressed [6]. Furthermore, the SDF-1-CXCR4 axis promotes paracrine tumor growth, enhances tumor cell invasiveness, induces tumor angiogenesis and attracts leukocytes [7, 8]. Recently, a novel receptor for SDF-1 has been identified, termed CXCR7/ RDC1 [9, 10], that binds in addition to SDF-1, I-TAC (interferon-inducible $\mathrm{T}$ cell $\alpha$ chemoattractant, CXCL11) but with tenfold lower affinity. As with CXCR4, CXCR7 is found on tumor and tumor-endothelial cells. CXCR7 is particularly highly expressed on breast, lung, prostate cancer and glioma cells [10-14]. Thus, a fluorescent SDF1-derivative would target tumors at several sites: the tumor vasculature and the tumor cells via CXCR4 and CXCR7.

\section{Experimental procedures}

Peptides, dyes and cells

Recombinant human SDF-1 $\alpha$ (CXCL12), CXCL16 and epidermal growth factor (EGF) were obtained from Preprotech, London, UK, other proteins from Sigma, St. Louis, MO, USA. Dipeptidyl peptidase IV (DPP IV)-truncated CXCL12 was prepared and purified as described for CXCL11 [15]. IRDye ${ }^{\circledR} 800 \mathrm{CW}-\mathrm{N}$-hydroxysuccinimide (NHS) ester was purchased from LI-COR, Lincoln, NE, USA. IntegriSense $680^{\circledR}$ which binds to the integrins $\alpha \mathrm{V} \beta 3 / \alpha \mathrm{V} \beta 5$ was purchased from VisenMedical (MA, USA). A764 glioma cell lines were obtained from a surgical tumor by dissociation and cultivation in Dulbecco's modified Eagle's medium (DMEM; Invitrogen, Carlsbad, CA, USA) plus $10 \%$ FCS [16], preparation and culture of other cell types have been described elsewhere [14, 17].

Peptide conjugation and purification

Peptides $(1 \mathrm{nmol})$ were incubated in $50 \mu \mathrm{l} 0.1 \mathrm{M} \mathrm{Na}_{2} \mathrm{CO}_{3}$ buffer, $\mathrm{pH} 8.6$, with $5 \mathrm{nmol}$ IRDye ${ }^{\circledR} 800 \mathrm{CW}-N$-hydroxysuccinimide ester dissolved in $5 \mu \mathrm{l}$ dimethyl sulfoxide for $2 \mathrm{~h}$ at room temperature in the dark. Excess reactive groups were saturated by addition of $2 \mu \mathrm{l} 1 \mathrm{M}$ Tris- $\mathrm{HCl}$ buffer, $\mathrm{pH}$ 8.6, and incubation for additional $15 \mathrm{~min}$. Then, conjugates were separated either by application on Sephadex G25 spin columns (GE Healthcare, Buckinghamshire, UK) and elution with $250 \mu \mathrm{l} 0.14 \mathrm{M} \mathrm{NaCl}$ in $20 \mathrm{mM}$ Hepes buffer, $\mathrm{pH} 7.4$, under centrifugation $(2 \mathrm{~min}, 1000 \times \mathrm{g})$ or (CXCL12-conjugate) by application on a Superdex Peptide 3.2/30 gel chromatography column (GE Healthcare) equilibrated and eluted with the above buffer. Fractions containing bound dye to peptide were combined and used for the experiments. Similar conjugations were made with a Cy3 NHS ester (GE Healthcare) to yield corresponding Cy3-conjugates.

Quantitative RT-PCR, analysis of kinase phosphorylation and other biological assays

For quantitative RT-PCR, RNA was isolated with the TRIZOL reagent, digested by DNase, cDNA synthesized and real time RT-PCR was performed [14] using TaqMan primer probes (Applied Biosystems, Foster City, CA, USA): hGAPDH (Hs99999905_m1), hCXCR4 (Hs00607 978_s1), hCXCR7 (Hs00664172_s1). Cycles of threshold $\left(\mathrm{C}_{\mathrm{T}}\right)$ were determined with a ABI PRISM 7000 sequence detection system, and $\Delta \mathrm{C}_{\mathrm{T}}$ values $=\mathrm{C}_{\mathrm{T}}$ Gene of interest$\mathrm{C}_{\mathrm{T}} \mathrm{GAPDH}$ were calculated. A $\Delta \mathrm{C}_{\mathrm{T}}$ value of 3.3 corresponds to one magnitude lower gene expression compared to GAPDH.

For kinase phosphorylation analysis, cells (70\% confluent) were washed twice with serum-free DMEM containing $1 \%$ (bovine serum albumin) BSA (each $1 \mathrm{~h}$ ) before stimulation that was done in fresh serum-free medium with $1 \%$ BSA. Stimulated cells were washed twice with ice-cold phosphate-buffered saline, lysed with Triton-lysis-buffer, lysates with equal amounts of proteins were separated by SDS-PAGE (10\%), blotted onto polyvinylidene difluoride membranes that were probed with anti-pErk1/2 (Thr202/ Tyr204; 1:500; Cell Signaling Technology, Danvers, MA, USA) and re-probed after stripping with methanol and $0.1 \mathrm{~mol} / \mathrm{l}$ glycine $/ \mathrm{HCl}$ buffer, $\mathrm{pH} 2.5$, with anti-Erk2 (1:500; Santa Cruz) using horseradish peroxidase-labeled anti-rabbit IgG (1:20,000; DAKO) and enhanced chemiluminescence visualization (ECL Advance ${ }^{\mathrm{TM}}$; GE Healthcare) as described [18].

\section{Binding experiments}

Cells cultivated for $24 \mathrm{~h}$ at different densities in 24-well plates were incubated in serum-free medium with NIRconjugates for the times and concentrations indicated. Then, cells were washed $(3 \times)$ with $0.14 \mathrm{M} \mathrm{NaCl} 20 \mathrm{mM}$ Hepes, $\mathrm{pH} 7.4$, followed by $4 \%$ BSA in this buffer. Cells were fixed with $4 \%$ paraformaldehyde in this buffer, and fluorescence determined and quantified with a Li-COR Odyssey Infrared Imaging system $\quad\left(\lambda_{\mathrm{Ex}}=785 \mathrm{~nm}\right.$; $\lambda_{\mathrm{Em}}=800 \mathrm{~nm}$ ). 
In vivo experiments

$2 \times 10^{6}$ tumor cells in phosphate-buffered saline were injected subcutaneously into FoxN1 immunodeficient mice, and tumors were allowed to grow for 7 days. Then, conjugates in $100 \mu \mathrm{l} 0.14 \mathrm{M} \mathrm{NaCl}$ in $20 \mathrm{mM}$ Hepes buffer, $\mathrm{pH} 7.4$, were injected in the tail vein under anesthesia, and NIR fluorescence visualized after different times with a LiCOR Pearl imager $\left(\lambda_{\mathrm{Ex}}=685\right.$ and $785 \mathrm{~nm} ; \lambda_{\mathrm{Em}}=702$ or $789 \mathrm{~nm})$. To reduce fluorescence background, animals were fed with low pheophorbide food.

\section{Statistical analysis}

Values are given as means \pm standard deviations of the mean (SD). Statistical significance was analyzed by ANOVA test; $* P<0.05, * * P<0.01, * * * P<0.001$.

\section{Results}

Synthesis of NIR-fluorescent conjugates

IRDye800CW was selected as optical fluorescence sensor for chemokine conjugates. It proved physicochemically stable in solution at neutral $\mathrm{pH}$ and yielded high fluorescence intensity (data not shown). The $N$-hydroxy-succinimide derivative was coupled in different molecular ratios to $\mathrm{SDF}-1(8 \mathrm{kDa})$ at $\mathrm{pH} 8.6$ and excess dye removed by gel filtration. A molar ration of 5:1 (dye:chemokine) in the conjugation was found optimal to achieve nearly complete conversion to the SDF-1-IRDye800CW conjugate. In spectophotometrical analyses of the purified conjugate the final dye/peptide ratio was between 0.5 and 1.1 . For nonspecific controls, corresponding conjugates of the chemokine CXCL16 (chemokine domain $10 \mathrm{kDa}$ ), of lactalbumin (14 kDa) and of BSA, (68 kDa) were synthesized. A conjugate of EGF was also used as a positive control for receptor binding.

Binding properties and selectivity of SDF-1-NIR-fluorescent conjugate

Prior to binding experiments, the transcription of the receptors for SDF-1 in endothelial and tumor cells were compared by quantitative RT-PCR (Fig. 1a). CXCR4 was transcribed at high rates in human umbilical vein endothelial cells (HUVEC) and MCF-7 breast cancer cells, moderately in MDA-MB-231 breast cancer, but not in glioma (U118, U343, A764) and HT29 colon carcinoma cells. In contrast, CXCR7 was highly transcribed in HUVEC, MCF-7, and glioma cells (U118, U34, A764 and others, compare [14]), but not in MDA-MB-231 and HT29 cells. Thus, HUVEC and MCF-7 are cells with high transcription of both $\mathrm{SDF}-1$ receptors while glioma cells have high transcription of only one receptor. Therefore, MCF-7 and A764 cells were selected for in vitro and in vivo binding and functional studies.

To evaluate the sensitivity and selectivity in vitro, increasing cell numbers were incubated for $1 \mathrm{~h}$ at $37^{\circ} \mathrm{C}$ with $100 \mathrm{nM}$ SDF-1-IRDye800CW conjugate and the NIRfluorescence measured and quantified (Fig. 1b). As few as 500 adherent cells could easily be detected. Fluorescence increased steadily with cell number, but was not completely linear (Fig. 1c). Under the same conditions, conjugates $(100-1,000 \mathrm{nM})$ of BSA (Fig. 1b, c), the chemokine CXCL16 or lactalbumin (not shown) yielded neither binding nor background. Furthermore, unlabeled SDF-1, but not the unrelated chemokine CXCL16 nor lactalbumin, displaced the SDF-1-conjugate dose-dependently from the cells (Fig. 1c). These experiments proof a high selectivity and a very low non-specific background of the label in vitro.

Labeling increased with concentration and time (Fig. 1). Time-dependency appeared saturable, but even after 15 min sufficient labeling was achieved. Concentrations of more than $10 \mathrm{nM}$ SDF-1-conjugate were necessary to achieve detectable labeling and saturation was observed with concentrations $>1000 \mathrm{nM}$. An alternate conjugate of EGF targeting the EGF receptor (EGFR) that is also overexpressed on A764 cells bound and displaced with a comparable affinity (data not shown). Receptor-mediated internalization of conjugates was studied in vitro with corresponding fluorescent Cy3-conjugates of SDF-1, EGF (positive control) and BSA (negative control) in A764 glioma cells bearing the receptors CXCR7 and EGFR. Conjugates of the bioactive peptides are found in the cells, whereas BSA-conjugate of BSA (negative control) is not taken up by the cells (Supplmentary Fig. 1).

\section{Biological properties of CXCL12-NIR-fluorescent conjugate}

For in vivo investigations, agonistic/antagonistic and toxic properties have to be evaluated. Biological activities of the ligand and conjugate were determined by analysis of the phosphorylation of the mitogen-activated protein kinase Erk1/2 (extracellular signal-related kinase) in A764 glioma cells that bear only CXCR7 (Fig. 2a). Whereas native CXCL12 induced a transient Erk1/2 phosphorylation comparable with EGF, the conjugate did not. As a control for loss of biological activity of the conjugate, SDF-1 was truncated proteolytically by incubation with dipeptidyl peptidase IV (DPP IV) liberating two N-terminal amino acids and yielding biologically inactive SDF-1 (3-67). Since the conjugate and also DPPIV-truncated SDF-1 

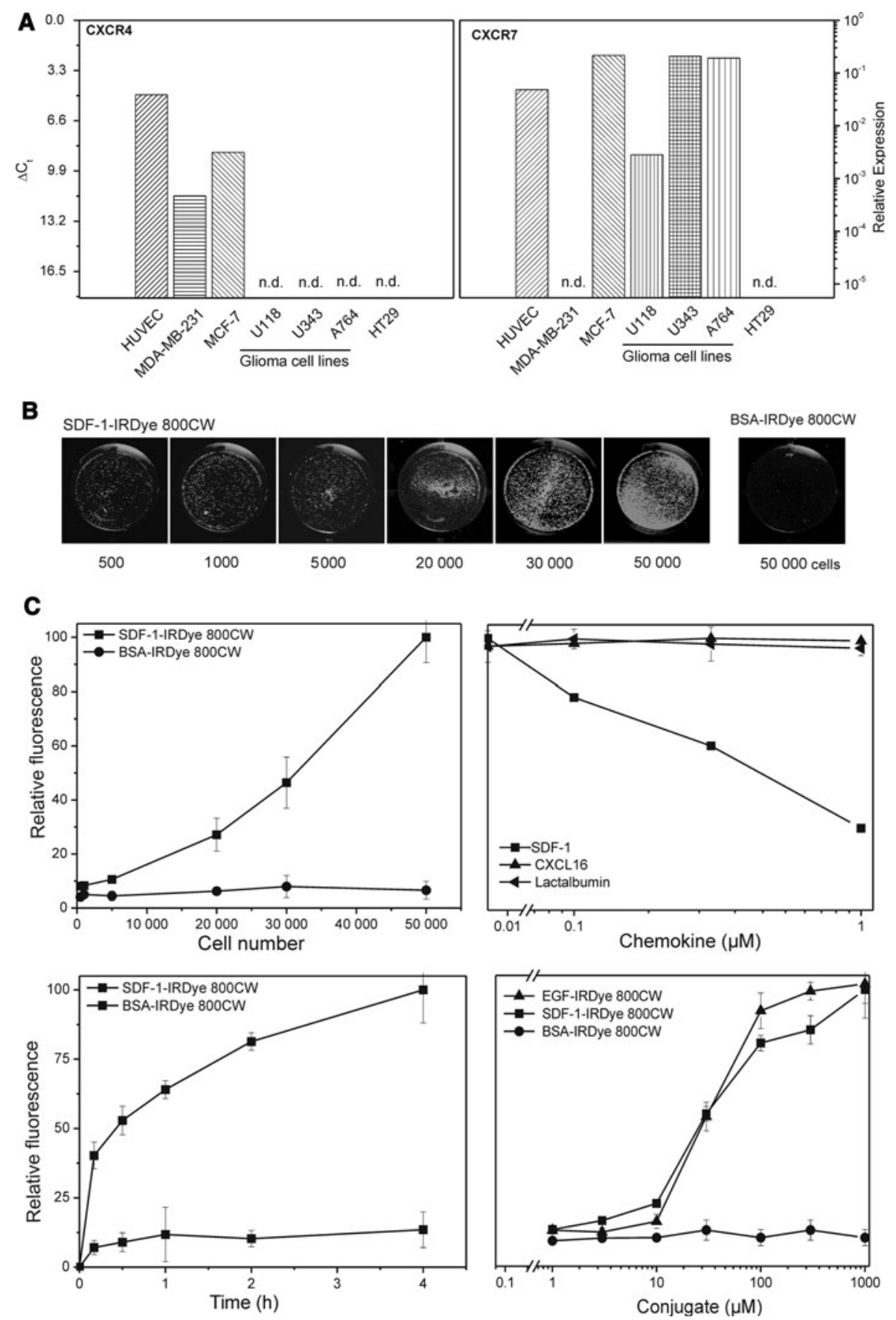

Fig. 1 Transcription of CXCR4 and CXCR7 in different tumor and endothelial cells and binding of NIR-fluorescent ligand SDF-1-IRDye $800 \mathrm{CW}$. a Transcription of the chemokine receptors in different cell types as determined by quantitative RT-PCR; $\Delta \mathrm{C}_{\mathrm{T}}$ values to GAPDH (glyceraldehyde-3-phosphate dehydrogenase) are given $\left(\Delta \mathrm{C}_{\mathrm{T}}=3.3\right.$ corresponds to one magnitude). CXCR4 and CXCR7 are highly transcribed both in human umbilical vein endothelial cells (HUVEC) and in MCF-7 breast cancer cells; CXCR4 is found at moderate levels in MDA-MB-231 breast cancer cells, but undetectable in glioma and HT29 colon carcinoma cells; CXCR7 is also highly transcribed in glioma cells, but not in MDA-MB-231 and HT29 cells. b Example of NIR-fluorescence labeling of tumor cells by SDF-1-IRDye $800 \mathrm{CW}$. Cultures of different numbers with A 764 glioma cells were exposed for $1 \mathrm{~h}$ at $37^{\circ} \mathrm{C}$ to $100 \mathrm{nM}$ SDF-1-IRDye $800 \mathrm{CW}$ or the

corresponding albumin (BSA) conjugate and NIR fluorescence visualized with an Odyssey Infrared Imaging system $\left(\lambda_{\mathrm{Ex}}=785 \mathrm{~nm}\right.$, $\lambda_{\mathrm{Em}}=800 \mathrm{~nm}$ ). As low as 500 cells can be detected by the specific ligand; the unspecific probe yields no background even with 50,000 cells. c Quantification of the NIR-fluorescence by bound SDF-1IRDye $800 \mathrm{CW}$ and controls on A764 glioma cells: top left, cell number dependency $\left(100 \mathrm{nM}, 1 \mathrm{~h}\right.$ at $\left.37^{\circ} \mathrm{C}\right)$, top right, displacement of bound SDF-1-IRDye $800 \mathrm{CW}(100 \mathrm{nM})$ by different concentrations of native SDF-1, CXCL16 (alternate chemokine) and lactalbumin (nonspecific control; $1 \mathrm{~h}$ at $37^{\circ} \mathrm{C}$ ); bottom left, time-dependency of binding $\left(100 \mathrm{nM}, 37^{\circ} \mathrm{C}\right)$, bottom right, concentration-dependency of SDF-1-IRDye 800CW-binding compared with EGF-IRDye $800 \mathrm{CW}$ (binding to EGFR on the cells) and BSA-IRDye 800CW (non-specifc control; all for $1 \mathrm{~h}$ at $37^{\circ} \mathrm{C}$ ) 
A
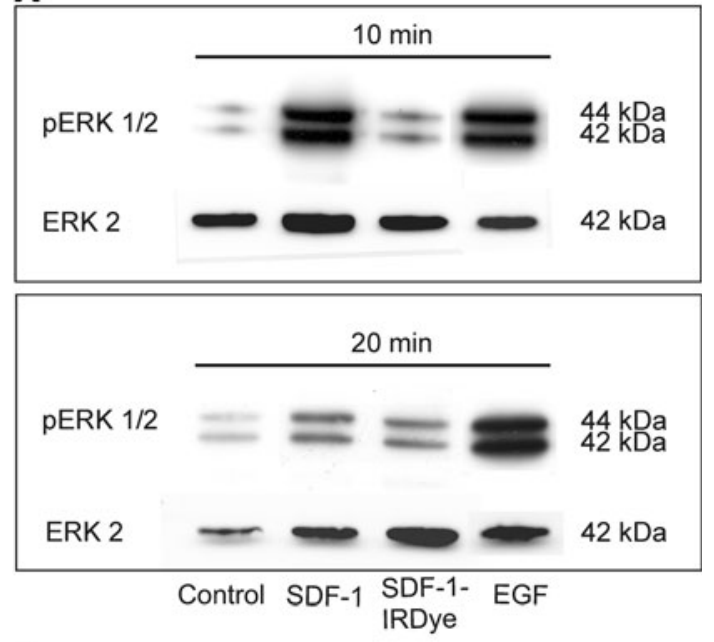

B

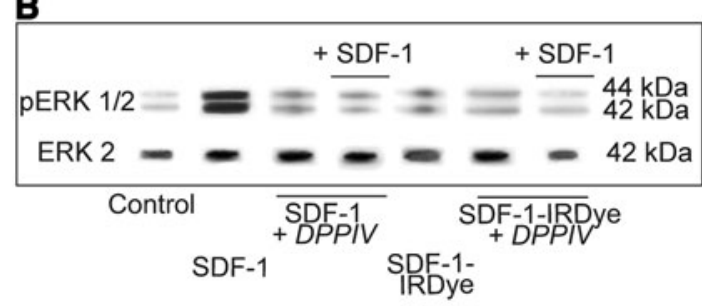

C

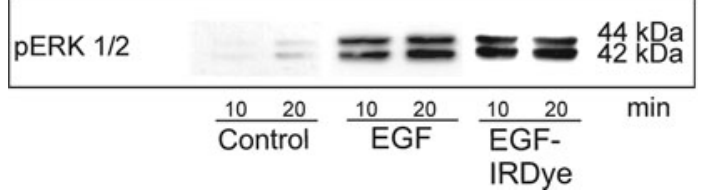

Fig. 2 Biological effects of SDF-1, epidermal growth factor (EGF) and their NIR-fluorescent conjugates. a Phosphorylation of extracellular-signal regulated kinases Erk1/2 after stimulation with the ligands $(10 \mathrm{nM})$ in $\mathrm{A} 764$ glioma cells for different times at $37^{\circ} \mathrm{C}$ was determined by Western blotting with chemoluminescence detection. Re-blots with antibody to Erk2 ensured equal loading of the gels. SDF-1 and EGF, but not SDF-1-IRDye 800CW induced transient Erk1/2 phosphorylation. b Antagonistic properties of SDF-1IRDye $800 \mathrm{CW}$ were ensured in corresponding experiments in which A764 cells were stimulated $\left(10 \mathrm{~min}, 37^{\circ} \mathrm{C}\right)$ with $10 \mathrm{nM}$ active SDF-1, inactive SDF-1(3-67) obtained by proteolytic cleavage with dipeptidyl peptidase IV (SDF-1 + DPP IV), SDF-1-IRDye 800CW or combinations. The SDF-1 effects are blocked by co-incubation with SDF-1(3-67) or SDF-1-IRDye 800CW. c In contrast to SDF-1-IRDye $800 \mathrm{CW}$, the EGF-IRDye $800 \mathrm{CW}$ was biologically active as the native peptide in this assay (10 $\mathrm{nM}$ peptide/conjugate)

failed to induce Erk1/2 phosphorylation, both, SDF-1-IRDye800CW and SDF-1 (3-67) behaved as antagonists (on CXCR7) which inhibited SDF-1-induced Erk 1/2 phosphorylation (Fig. 2b). In contrast to the SDF-1-conjugate, a corresponding EGF-conjugate was still biologically active (via EGFR) as with native EGF (Fig. 2c).

In further biological assays, the effects of SDF-1 and its conjugate on cell proliferation (DNA quantification) and cell integrity (release of the cytosolic enzyme lactate dehydrogenase, LDH) of A764 glioma cells were measured (not shown). Both did not influence proliferation nor were they cytotoxic in these assays. Thus, SDF-1-IRDye $800 \mathrm{CW}$ is biologically inactive and non-toxic by in vitro assays.

Visualization of tumors in vivo

In normal mice, the dye distributed rapidly through the bodies and was nearly totally cleared within $24 \mathrm{~h}$ (Supplmentary Fig. 2). For detection of tumors, immunodeficient nude mice were inoculated subcutaneously with two million human MCF-7 or A764 cells, and after one week tumors visualized by injection of $0.1 \mathrm{nmol}$ SDF-1-IRDye800CW (Fig. 3). After $1 \mathrm{~h}$, the tumors as well as the liver, skull and bone marrow of the hind legs were labeled by the conjugate. After 24-92 h, background diminished and tumors were still clearly visible. Thus, the SDF-1conjugate labels tumors and yields fluorescence for up to 4 days. Nonspecific labeling is mainly observed in liver and skull (probably the skin over the skull since the brain was not labeled). Labeling of the bone marrow might be a specific reaction, since CXCR4 is known to be expressed in hematopoietic stem cells.

To evaluate the sensitivity and efficacy of tumor labeling, the SDF-1-IRDye800CW conjugate was compared to IntegriSense $680^{\circledR}$ that targets mainly $\alpha_{\mathrm{V}} \beta_{3} / \alpha_{\mathrm{V}} \beta_{5}$ integrins of the tumor vasculature (Fig. 4). In animals bearing subcutaneous MCF-7 tumors both conjugates efficiently labeled the tumor, but a 20 -fold higher concentration of the Integrisense $^{\text {TM }} 680$ was required (Fig. 4a). After 24 h, IntegriSense $680^{\circledR}$ displayed less background in the liver than the SDF-1-conjugate, but a little more background in lungs and some other vascularized tissues (Fig. 4a). In mice inoculated with MCF-7 and A764 cells at different sites, both tumors were detected with the SDF-1-conjugate, whereas the MCF-7 tumor was visualized only with IntegriSense $680^{\circledR}$. Resection of the animals revealed vascularized subcutaneous tumors of MCF-7 cells whereas solid A764 tumors could not be recovered due to their very small size. This shows that only vascularized solid tumors, but not discrete tumors cells/cell aggregates can be visualized by IntegriSense $680^{\circledR}$ whereas non-vascularized small tumors/tumor cells aggregates can be detected by SDF-1-conjugates.

\section{Discussion}

Optical imaging of tumors by selective molecular probes provides comparatively simple, noninvasive visualization of tumors and their metastases. In preclinical models, such methods can be used to monitor tumor growth, invasion, angiogenesis and spreading and are especially applicable for therapeutic testing. In humans, optical imaging methods 
Fig. 3 Visualization of subcutaneous tumors in mice by injection of CXCL12-IRDye $800 \mathrm{CW}$ (time course). MCF-7 breast tumor and A764 glioma cells were implanted subcutaneously into the right respectively left flanks of FoxN1 mice. After 6 days, $0.1 \mathrm{nmol}$ SDF-1-IRDye $800 \mathrm{CW}$ was injected into the tail vein and NIR fluorescence monitored after different time with a Pearl Imager. After 24-96 h, subcutaneous tumors (arrows) were good visible, but also liver, brain and bone marrow were labeled. Most of the nonspecific labeling diminished after $24 \mathrm{~h}$; the tumors retained the label up to $92 \mathrm{~h}$
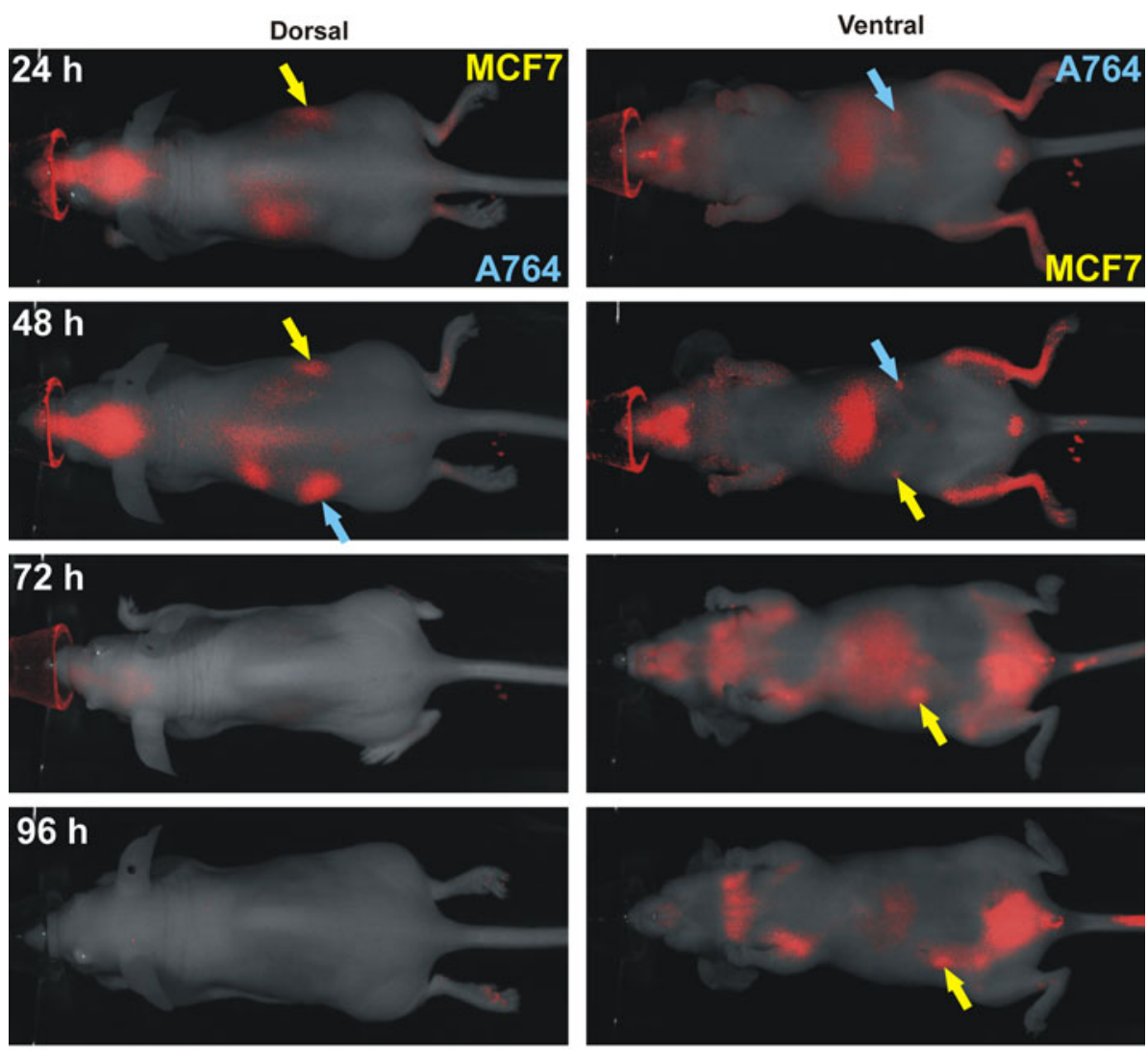

SDF-1-IRDye $800 \mathrm{CW}(0.1 \mathrm{nmol})$

could also improve cancer diagnosis, detection of tumor cells under surgery and control the completeness of surgical resection as a principal component of current cancer therapy. NIR fluorescence-based optical imaging is a newer imaging technique that allows sensitive detection based on highly fluorescent dyes and deep tissue penetration because of the low absorption of light by biological tissues in the "NIR window" between 650-900 nm [1]. Visible light is absorbed abundantly by tissue chromophores, in particular hemoglobin, whereas infrared light is partly adsorbed by water and lipids. Consequently wavelengths in the NIR window can penetrate tissues up to a few centimeters. Targeted probe approaches have the advantage of far better tumor to background ratio and provide specific molecular information that may distinguish tumors from other pathological alterations, mirror different stages/types of malignancies or inform about the suitability of pharmacological therapies.

Growth factor or chemokine receptors as molecular targets for tumor probes have the advantage that they are directly involved in tumor growth, angiogenesis, spreading and metastasis [19]. Among chemokines, the SDF-1CXCR4/7 axis is of particular importance in tumor biology. SDF-1 is produced by mesenchymal cells in peripheral tissues and attracts CXCR4-positive tumor cells [6]. In addition to metastasis, SDF-1 supports paracrine tumor growth, tumor cell invasiveness, tumor angiogenesis and leukocyte attraction [5, 8]. The novel SDF-1 receptor, CXCR7 and additionally CXCR4 are expressed on the tumor vasculature and on distinct tumor cells. The biological role of CXCR7 is, however, not yet been fully clarified [9, 10, 14]. Thus, CXCR4/7-directed NIR-fluorescence probes label tumors at dual sites: on the tumor endothelial cells and on some (CXCR4- and/or CXCR7positive) tumor cells. As a model system of tumor cells that express either one or both receptors at high levels, we chose MDF-7 breast cancer and A764 glioma cells.

In vitro, SDF-1-cyanine dye conjugates showed high selectivity and sensitivity. The cyanine-dye IRDye ${ }^{\circledR} 800 \mathrm{CW}$ was chosen because of its high quantum yield, chemical and physical stability and low toxicity [20]. A SDF-1-Cy7 conjugate exhibited similar biological properties, but yielded less fluorescence response (data not presented). IRDye ${ }^{\circledR} 800 \mathrm{CW}$-conjugates targeting different molecules, e. g. a EGF or 2-deoxyglucose conjugates, have been previously prepared and effectively used to detect tumor cells in vitro and in vivo [21, 22]. Using our SDF-1-NIR-fluorescentconjugate we could detect as low as 500 cells in vitro. Unrelated chemokines or non-specific (albumin) conjugates showed no background in vitro, even at higher cell numbers 


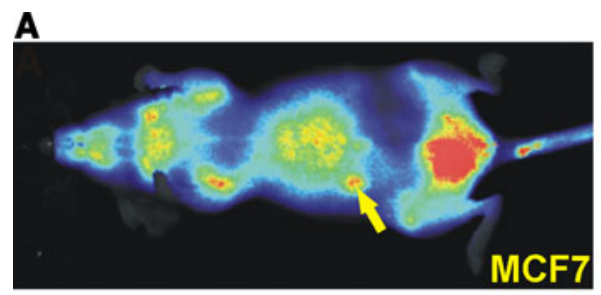

SDF-1-IRDye $800 \mathrm{CW}(0.1 \mathrm{nmol})$

$\mathbf{B}$

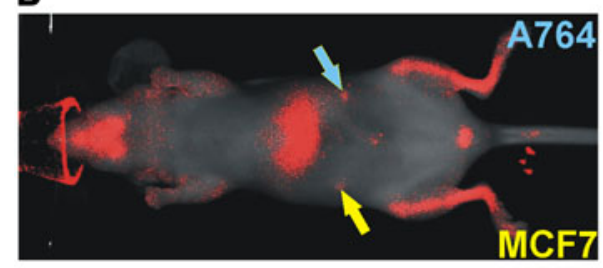

SDF-1-IRDye $800 \mathrm{CW}(0.1 \mathrm{nmol})$

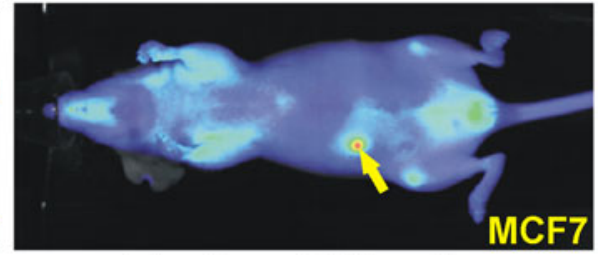

IntegriSense $680(2 \mathrm{nmol})$

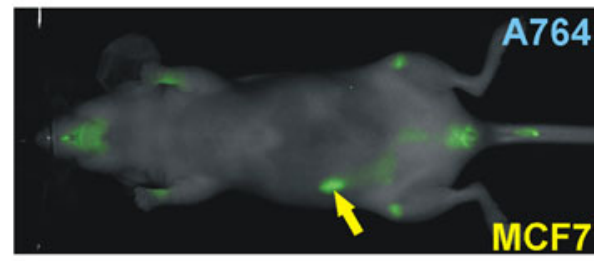

IntegriSense 680 (2 $\mathrm{nmol})$

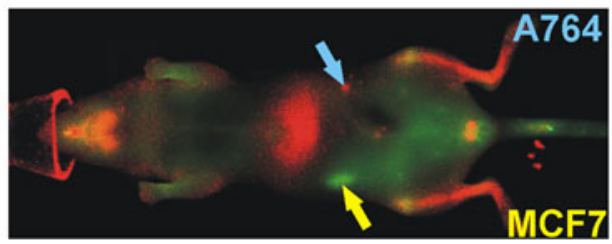

Combination

Fig. 4 Comparison of the visualization of subcutaneous tumors in mice after injection of $0.1 \mathrm{nmol}$ SDF-1-IRDye $800 \mathrm{CW}$ and $2 \mathrm{nmol}$ IntegriSense $680^{\circledR}$ (integrin $\alpha_{\mathrm{V}} \beta_{3} / \alpha_{\mathrm{V}} \beta_{5}$-targeting NIR-fluorescent dye). MCF-7 breast tumor alone or additionally A764 glioma cells were implanted subcutaneously into FoxN1 mice. After 6 days, dyes were injected into the tail vein and NIR fluorescence monitored with a Pearl Imager. a Visualization of different labeling intensities. b Visualization of the two dyes at their optimal emission wavelengths

or in higher concentrations applied. Furthermore, the SDF-1conjugate could be dose-dependently displaced from its receptor by the unlabeled peptide.

In mice, the SDF-1-conjugate distributed rapidly and then was cleared. Similar biodistribution was observed with a ${ }^{99 m}$ Tc-radiolabeled SDF-1-construct in rats [23] and with a ${ }^{64} \mathrm{Cu}$-radiolabeled AMD3100-conjugate [24] that labels mainly CXCR4. After intravenous injection, a half life of about 26 min was observed for the radiolabeled SDF-1-conjugate, and after $2 \mathrm{~h} 74 \%$ of this label was observed in the urine. Despite highly sensitive detection of inflammatory and (metastatic) tumor cells, radioactive SDF-1-conjugates have the clear disadvantage that they also target tissues which are highly sensitive to radiation, namely hematopoietic stem cells in the bone marrow, where SDF-1 functions in recruiting homing and quiescence [25]. Supporting this role, in most animals our SDF1 -IRDye ${ }^{\circledR} 800 \mathrm{CW}$ conjugate labeled also bone marrow in addition to tumors. Transient, non-specific labeling in the first $24 \mathrm{~h}$ was observed in the liver and skull.

As side effects, growth factor or chemokine conjugates used for diagnostics can maintain tumor growth on their
$\lambda_{\mathrm{Ex}}=685 \mathrm{~nm}, \lambda_{\mathrm{Em}}=702 \mathrm{~nm}$ for IntegriSense $680^{\circledR}$ (as indicated), respectively $\lambda_{\mathrm{Ex}}=785, \lambda_{\mathrm{Em}}=789 \mathrm{~nm}$ for IRDye800 CW (as indicated), or combination. Both dyes labeled the MCF-7 tumor, but only SDF-1-IRDye $800 \mathrm{CW}$ the A764 tumor cells (that were not detectable under resection). The SDF-1 conjugate yielded sensitive visualization even at 20 -fold lower concentrations. The IntegriSense $680^{\circledR}$ showed somewhat lower background in the liver, but higher in the lung

own unless they target inhibitory receptors (e. g. somatostatin receptors) or lose biological activity. In contrast to a corresponding EGF-conjugate, our SDF-1-conjugate showed antagonistic properties in signal transduction assays. It is well known that small modifications of SDF-1 and other chemokines can result in loss of biological activities while binding activity is maintained. For e.g., removal the two $\mathrm{N}$-terminal amino acids of the 67-residue peptide SDF-1 by the ubiquitous cell surface protease dipeptidyl peptidase IV (DPP IV, CD26) converts it to an antagonist [26]. Furthermore, position and type of fluorescent label appear to influence binding activities, at least for short peptide analogues [27]. Synthetic CXCR4-antogonists like Plerixafor (AMD3100, non-peptide) or T140 (peptide) have been developed initially for the treatment of HIV, where CXCR4 functions as a co-receptor for virus entry into $\mathrm{T}$ cells. They are also under preclinical and clinical evaluation for the treatment of leukemias/lymphomas, melanomas, glioblastomas, breast, small cell lung, pancreatic, gastric and prostate cancers [8]. Consequently, these types of tumors are well suited for imaging by SDF1-NIR fluorescent probes. Other applications include the 
detection of myocardial infarction [23] and chronic inflammatory diseases.

In summary, NIR-fluorescent conjugates of SDF-1 (and also synthetic antagonists) show a high selectivity, specificity and sensitivity in vitro and in vivo for tumor detection. In vivo, the conjugate rapidly distributes and is cleared by the kidney. Experimental tumors are specifically labeled, and the signals persist over days.

Acknowledgments We thank Martina Burmester and Miriam Lemmer for expert technical assistance. This work was supported by grants from the State of Schleswig-Holstein "Molecular Imaging in the North", by the Federal Government BMBF "TOMCAT" and by the „Werner und Klara Kreitz-Stiftung“.

Open Access This article is distributed under the terms of the Creative Commons Attribution Noncommercial License which permits any noncommercial use, distribution, and reproduction in any medium, provided the original author(s) and source are credited.

\section{References}

1. Mahmood U, Weissleder R (2003) Near-infrared optical imaging of proteases in cancer. Mol Cancer Ther 2:489-496

2. Ogawa M, Kosaka N, Choyke PL, Kobayashi H (2009) In vivo molecular imaging of cancer with a quenching near-infrared fluorescent probe using conjugates of monoclonal antibodies and indocyanine green. Cancer Res 69:1268-1272

3. Ke S, Wen X, Gurfinkel M, Charnsangavej C, Wallace S, SevickMuraca EM, Li C (2003) Near-infrared optical imaging of epidermal growth factor receptor in breast cancer xenografts. Cancer Res 63:7870-7875

4. Chen X, Conti PS, Moats RA (2004) In vivo near-infrared fluorescence imaging of integrin alphavbeta3 in brain tumor xenografts. Cancer Res 64:8009-8014

5. Vandercappellen J, Van Damme J, Struyf S (2008) The role of CXC chemokines and their receptors in cancer. Cancer Lett 267:226-244

6. Müller A, Homey B, Soto H, Ge N, Catron D, Buchanan ME, McClanahan T, Murphy E, Yuan W, Wagner SN, Barrera JL, Mohar A, Verástegui E, Zlotnik A (2001) Involvement of chemokine receptors in breast cancer metastasis. Nature 410:50-56

7. Ethesham M, Winston JA, Kabos P, Thompson RC (2006) CXCR4 expression mediates glioma cell invasiveness. Oncogene 25:2801-2806

8. Burger JA, Peled A (2009) CXCR4 antagonists: targeting the microenvironment in leukemia and other cancers. Leukemia 23:43-52

9. Balabanian K, Lagane B, Infantino S, Chow KY, Harriague J, Moepps B, Arenzana-Seisdedos F, Thelen M, Bachelerie F (2005) The chemokine SDF-1/CXCL12 binds to and signals through the orphan receptor RDC1 in T lymphocytes. J Biol Chem 280:35760-35766

10. Burns JM, Summers BC, Wang Y, Melikian A, Berahovich R, Miao Z, Penfold ME, Sunshine MJ, Littman DR, Kuo CJ, Wei K, McMaster BE, Wright K, Howard MC, Schall TJ (2006) A novel chemokine receptor for SDF-1 and I-TAC involved in cell survival, cell adhesion, and tumor development. J Exp Med 203:2201-2213
11. Miao Z, Luker KE, Summers BC, Berahovich R, Bhojani MS, Rehemtulla A, Kleer CG, Essner JJ, Nasevicius A, Luker GD, Howard MC, Schall TJ (2007) CXCR7 (RDC1) promotes breast and lung tumor growth in vivo and is expressed on tumor-associated vasculature. Proc Natl Acad Sci 104:15735-15740

12. Wang J, Shiozawa Y, Wang J, Wang Y, Jung Y, Pienta KJ, Mehra R, Loberg R, Taichman RS (2008) The role of CXCR7/ $\mathrm{RDC} 1$ as a chemokine receptor for CXCL12/SDF-1 in prostate cancer. J Biol Chem 283:4283-4294

13. Luker KE, Steele JM, Mihalko LA, Ray P, Luker GD (2010) Constitutive and chemokine-dependent internalization and recycling of CXCR7 in breast cancer cells to degrade chemokine ligands. Oncogene 29:4599-4610

14. Hattermann K, Held-Feindt J, Lucius R, Sebens Müerköster S, Penfold MET, Schall TJ, Mentlein R (2010) The chemokine receptor CXCR7 is highly expressed in human glioma cells and mediates anti-apoptotic effects. Cancer Res 70:3299-3308

15. Ludwig A, Schiemann F, Mentlein R, Lindner B, Brandt E (2002) Dipeptidyl peptidase IV (CD26) on T cells cleaves the CXC chemokine CXCL11 (I-TAC) and abolishes the stimulating but not the desensitizing potential of the chemokine. J Leukoc Biol 72:183-191

16. Mentlein R, Eichler O, Forstreuter F, Held-Feindt J (2001) Somatostatin inhibits the production of vascular endothelial growth factor (VEGF) in glioma cells. Int J Cancer 92:545-550

17. Oxmann D, Held-Feindt J, Stark AM, Hattermann K, Yoneda T, Mentlein R (2008) Endoglin expression in metastatic breast cancer cells enhances their invasive phenotype. Oncogene 27: $3567-3575$

18. Hattermann K, Ludwig A, Gieselmann V, Held-Feindt J, Mentlein R (2008) The chemokine CXCL16 induces migration and invasion of glial precursor cells via its receptor CXCR6. Mol Cell Neurosci 39:133-141

19. Schottelius M, Wester HJ (2009) Molecular imaging targeting peptide receptors. Methods 48:161-177

20. Kovar JL, Simpson MA, Schutz-Geschwender A, Olive DM (2007) A systematic approach to the development of fluorescent contrast agents for optical imaging of mouse cancer models. Anal Biochem 367:1-12

21. Kovar JL, Volcheck WM, Chen J, Simpson MA (2007) Purification method directly influences effectiveness of an epidermal growth factor-coupled targeting agent for noninvasive tumor detection in mice. Anal Biochem 361:47-54

22. Kovar JL, Volcheck W, Sevick-Muraca E, Simpson MA, Olive DM (2009) Characterization and performance of a near-infrared 2-deoxyglucose optical imaging agent for mouse cancer models. Anal Biochem 384:254-262

23. Misra P, Lebeche D, Ly H, Schwarzkopf M, Diaz G, Hajjar RJ, Schecter AD, Frangioni JV (2008) Quantitation of CXCR4 expression in myocardial infarction using 99mTc-labeled SDF1alpha. J Nucl Med 49:963-969

24. Nimmagadda S, Pullambhatla M, Stone K, Green G, Bhujwalla ZM, Pomper MG (2010) Molecular imaging of CXCR4 receptor expression in human cancer xenografts with [64Cu]AMD3100 positron emission tomography. Cancer Res 70:3935-3944

25. Zou YR, Kottmann AH, Kuroda M, Taniuchi I, Littman DR (1998) Function of the chemokine receptor CXCR4 in haematopoiesis and in cerebellar development. Nature 393:595-599

26. Mentlein R (2004) Cell-surface peptidases. Int Rev Cytol 235: $165-213$

27. Oishi S, Masuda R, Evans B, Ueda S, Goto Y, Ohno H, Hirasawa A, Tsujimoto G, Wang Z, Peiper SC, Naito T, Kodama E, Matsuoka M, Fujii N (2008) Synthesis and application of fluorescein- and biotin-labeled molecular probes for the chemokine receptor CXCR4. Chembiochem 9:1154-1158 